\title{
ent orno
}

\section{"Para que los Estados} funcionen hay que trabajarlos mucho y por bastante tiempo"

No hay recetas ni claves para que una política fiscal funcione, más bien los Estados deben de trabajar arduamente, basados en investigaciones y datos certeros de cómo es la situación propia, asegura el economista español Andrés Sanz, director de programas del Instituto de Estudios Fiscales de España.

Camila Calles

Docente Investigadora de la UTEC

$\mathbf{F}$

economista español Andrés Sanz llegó al país para cerrar el diplomado en Política Fiscal que la Facultad de Maestrías y Estudios de Postgrados, en coordinación con la Fundación Nacional para el Desarrollo (FUNDE), realizó por tres meses.

Sanz es el actual director de programas del Instituto de Estudios Fiscales de España, entidad suscrita al gobierno de esa nación y desde donde nacen propuestas concretas para crear y poner en práctica políticas públicas fiscales.

Este economista español no duda en afirmar que el buen funcionamiento de la política fiscal en un determinado país tiene que basarse en la investigación, por ello es necesario crear instancias destinadas a eso y con ello unir a la academia con la administración pública. A través de las investigaciones se podrá proponer mecanismos de mejora en la creación de políticas públicas en el país. Esos mecanismos tendrán que apuntar a crear espacios propicios en los que la información se ponga a disposición de los ciudadanos.

De igual forma, establece que la transparencia en el manejo de las finanzas públicas debe de ser una forma del comportamiento normal de las instituciones públicas.

¿Cuál es la labor del Instituto de Estudios Fiscales?

El Instituto de Estudios Fiscales se crea a principio de los 60 con un único y fundamental objetivo de ser un ejemplo que sirviera al cambio de la hacienda española. En aquella época,

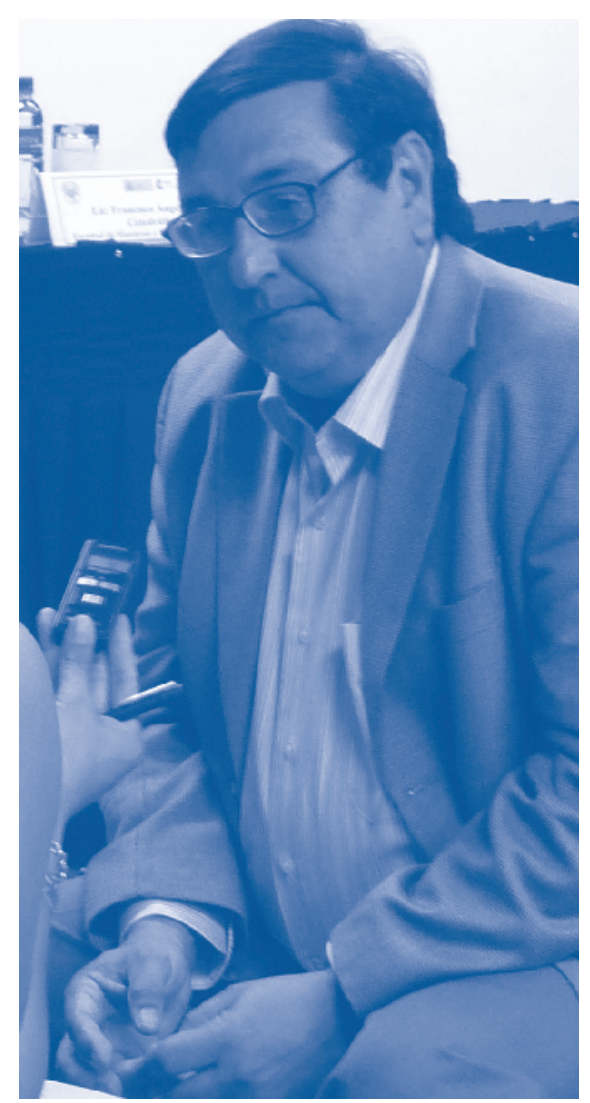




\section{De igual forma, establece que la transparencia en el manejo de las finanzas públicas debe de ser una forma del comportamiento normal de las instituciones públicas.}

en España sucede un cambio en la administración con un movimiento que se denominó: 'los tecnócratas', que intentaron, a pesar de lo que se vivía en el país, modernizarlo en el área de la administración y un tema de la hacienda, que sabía que era clave. Crearon un instituto que tenía como funciones hacer investigaciones, estudios y exploramientos para ir viendo las nuevas técnicas, las formas de manejar la hacienda pública y ese es el origen de Instituto de Estudios Fiscales. Posteriormente, se une la escuela de la hacienda pública, que funciona para la formación y selección de los funcionarios del Ministerio de Economía y Hacienda de España. Ahora tenemos esos dos componentes: el Instituto, que es el que realiza investigación, investigación aplicada no teórica para el asesoramiento y estudios al servicio de la hacienda española; y un centro de selección y formación de funcionarios relacionados con la hacienda. La selección la hacemos solo a nivel central de gobierno, pero la formación y la investigación

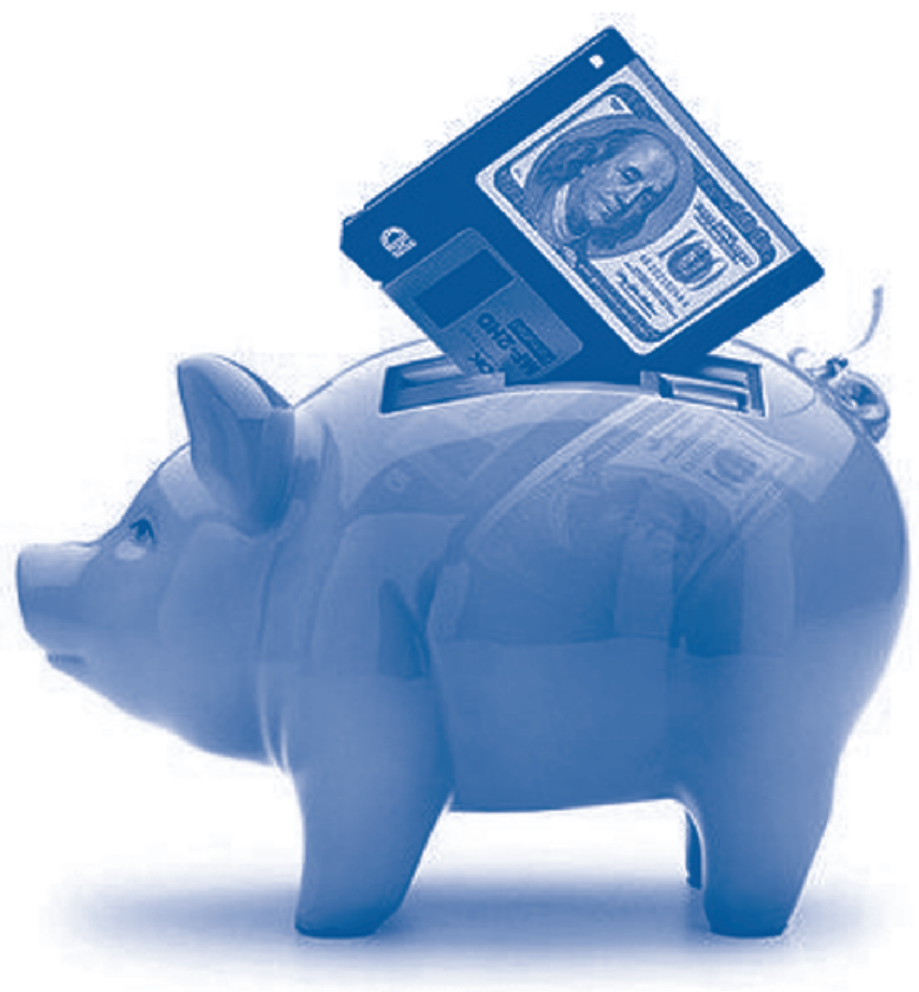

la hacemos para todas las entidades del gobierno.

\section{¿Qué áreas de trabajo específicas tienen?}

En el área de formación y en el de investigación. En el de formación es en la parte formal, es entre ingresos y gastos y en investigación es presupuesto y gastos y estudios tributarios. El área de investigación es mucho más amplia, pues el área de presupuesto es un tema que siempre está y en el área de formación y selección están un poco separada, pero también porque realmente se están abordando muchos temas que pertenecen al área presupuestaria. Ahora bien, nosotros nos dedicamos a la hacienda pública en el sentido más amplio. Vemos el impacto redistributivo de las políticas públicas o evaluación de políticas sanitarias, todo lo que tiene que ver con la hacienda pública en el sentido más amplio, sin entrar mucho en los aspectos macros de la política fiscal, porque eso corresponde a otras áreas del ministerio. La hacienda pública está en proceso de cambios fundamentales, entonces el instituto ha tenido protagonismo. En el instituto están las diferentes comisiones que se crean para estudiar estas cosas, incidimos como centro de estudios en está área.

\section{¿En que radica el éxito de la política fiscal española?}

En el área de la hacienda pública. Es algo que se puede hacer porque realmente nosotros teníamos una hacienda pública bastante débil en dos áreas: bajo ingreso y capacidad de recaudación bastante baja, y un montón de políticas públicas en todas las áreas que no engranaban. Entonces, cómo se logró. Entre 


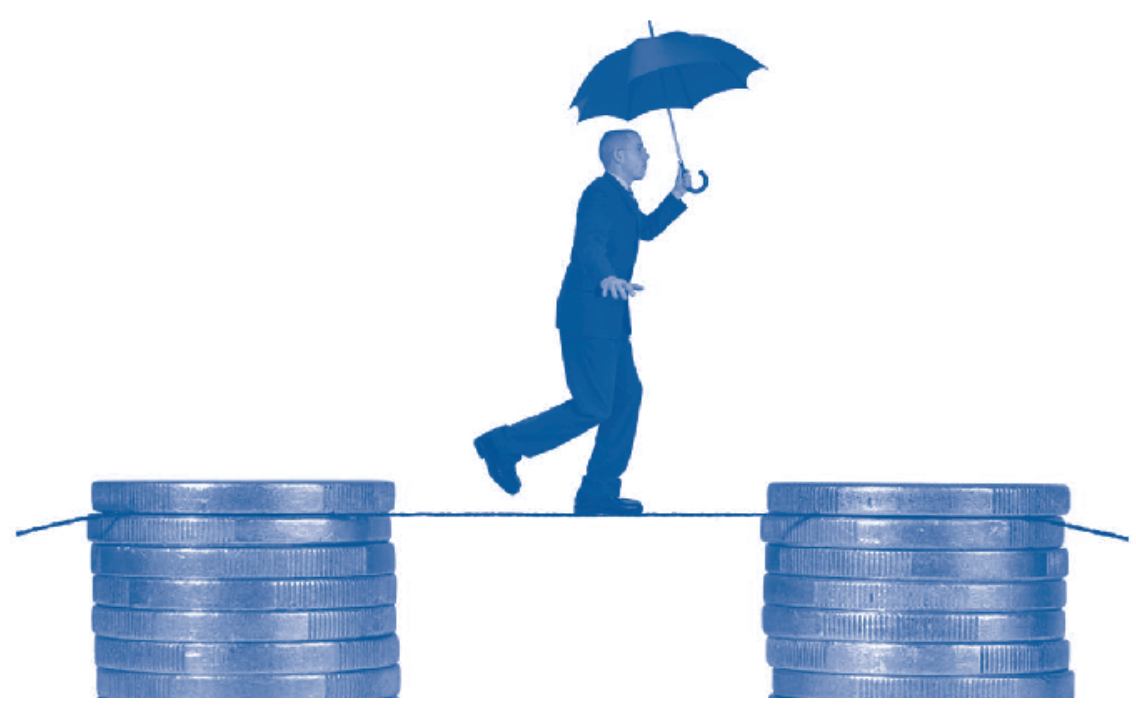

otras cosas, haciendo instituciones como esta (el Instituto de Estudios Fiscales). El gran acierto que tuvieron los fundadores del instituto fue que en un momento que era raro hacer estas cosas, pensar que el mundo iba a cambiar y que iba a ser tan necesaria la investigación y un centro que generara estudios, ir generando cuadros que eran capaces de ayudar al cambio, de propiciar el cambio y luego fue una idea muy clara de, aunque nosotros pertenecemos al ministerio de economía y hacienda, somos una institución autónoma. El instituto ha creado un perfil en la hacienda española. Somos una institución que no se asocia al gobierno. Eso se ha logrado esté quien esté en la composición de nuestros grupos de trabajo que son muy plurales ideológicamente.

\section{¿Cómo han logrado esa independencia?}

Quizás ha sido por una mezcla muy interesante, y que yo recomiendo a todos los que quieran hacer esto (de crear un Instituto de Estudios Fiscales), de academia y administración pública. Ese sería el elemento más interesante. Uno de los primeros directores del instituto, César Albiñana, era a la vez inspector de hacienda y catedrático de hacienda. Eso ha sido una tradición. Ha habido directores que han sido o funcionarios del ministerio y que han sido catedráticos. Ya llevamos varios catedráticos y no solo de hacienda, pues nos damos cuenta que el asunto de hacienda no solo es un tema que compete a los hacendistas, sino que hay otras áreas involucradas, y se trabaja el sector público con todos sus especialistas. El punto fuerte fue haber hecho esa unión entre academia y administración pública, y luego haber generado una tradición importante en la selección y formación de los funcionarios públicos, que tampoco era especialmente complicada porque la tradición española proviene de la francesa y entonces la forma de ingreso a la administración es a través de una oposición y luego se complementa con la formación en nuestro centro. El instituto es visto como un referente por su formación, por su trabajo. Se editan revistas y es una institución que los que estamos ahí la queremos. Es muy bonito por estar en un lugar que te paguen por lo que te gusta y que además tiene una gran incidencia a nivel nacional.

Ahí está, entonces, la importancia de la inclusión de la academia en la creación de políticas públicas

Es una mezcla muy positiva. La gente de la universidad está trabajando en el instituto.

\section{¿Cómo hacer para que una política fiscal funcione?}

Lo primero es que las políticas fiscales son complejas y que lo que tenemos hoy es el resultado de lo que hemos hecho en el pasado. No hay ninguna posibilidad de cambiar las cosas rápidamente, eso es algo muy importante. Yo le agradezco a los fundadores del instituto que se dieron cuenta de eso, que para que los Estados funcionen hay que trabajarlo mucho y por bastante tiempo, hay que darle cultura, hay que dar buenos salarios, hay creación de instituciones y hay suerte, porque en ocasiones es suerte en donde estemos ubicados. Por ejemplo, el que nosotros estemos en la Comunidad Europea nos favorece más que a ustedes que no están. No hay recetas, para lo que sí hay recetas es que si usted tiene un Estado fuerte, bien organizado y los procesos de selección y acceso a la administración pública son lo más objetivos posibles es probable que su Estado funcione bien y que se hagan políticas fiscales y públicas al margen de las condiciones concretas del país. El mecanismo de selección es fundamental para mí, que la selección esté basada en criterio de 
mérito y capacidad, que sea pública y transparente. No hay recetas.

Si bien no hay recetas, pero hay medidas que nos pueden ayudar a mejorar la situación. ¿Qué medidas, por ejemplo, nos puede llevar a que realmente se maneje de manera transparente la hacienda pública?

Creo que el tema de la transparencia es también compleja. Si le llamamos transparencia a tener información de las cuentas, pues entonces eso está bien. Entonces son medidas hacer que nos muestren las cuentas, pero también nos hace falta una cultura en la administración pública: por parte de los funcionarios que les guste informar sobre eso; por otro lado, no solamente que nos den información, si no que puede ser más complicado, porque también depende de qué es lo que se va a dar a conocer. A mí como ciudadano me puede interesar para qué ha servido lo que he gastado, pero eso no depende solo de darlos a conocer o no darlos a conocer, sino más bien que se sepa o no se sepa. Para saber hacer eso, hace falta dos cosas: invertir en un sistema de información, que no se hace de la noche a la mañana; invertir en gente que sepa hacer eso, por lo tanto falta dedicarse a crear una demanda de esa información. De qué sirve crear algo que a nadie le interesa. Es importante que los ciudadanos tengan interés de conocer qué se hace en la hacienda pública, pero no solo en aspectos contables sino que también en términos de eficiencia y eficacia. Parte importante para nosotros (los españoles) es que después de la reforma constitucional se estableció en el 31-2 de nuestra Constitución los criterios a los que debe de ajustarse los gastos públicos. Ahí tenemos como algo importante: ¿quién introdujo ese artículo?. Uno de los directores generales que tuvo nuestro instituto, Enrique Fuentes Quintana, quien en ese momento era senador e introdujo la enmienda al senado. Entonces, ya ve que es importante crear instituciones como esta (Instituto de Estudios Fiscales de España) en las que se piensa y si se piensa se pueden hacer propuestas que valgan la pena. Esa enmienda nos fija el marco de actuación del gasto público y luego nos sirve para que cuando como ciudadanos podamos pedir como derecho.

Otro gran reto, dentro de las políticas fiscales es lidiar con la deuda pública. No se pude eliminar de un día para otro, pero ¿cómo lidiar con la deuda pública?

Atacar el problema de la deuda directamente es complicado, pero se puede hacer por el otro lado. Le voy a plantear lo siguiente y usted me dirá: podemos tener un sistema tributario interesante, decente $y$ equitativo y una gestión tributaria eficiente, con ello estamos atacando en los ingresos. Podemos tener un sistema de gestión de ingresos eficiente, decente y equitativa, con esas dos cosas estamos atacando la deuda.

\section{¿Generando más ingresos?}

Generando más ingresos. Generando un gasto mucho más eficaz, eficiente y equitativo me va generar más crecimiento. El Estado es un agente que favorece la competitividad de su país o no la favorece, Esas dos cosas nos van ayudar a atacar o resolver.

\section{¿Una medida sería aumentar los impuestos?}

Es que no conozco el caso concreto de El Salvador. Una persona que trabaja en una institución como en la que trabajo debe de ser muy riguroso. Si aumentar los impuestos es que el volumen de ingresos sobre

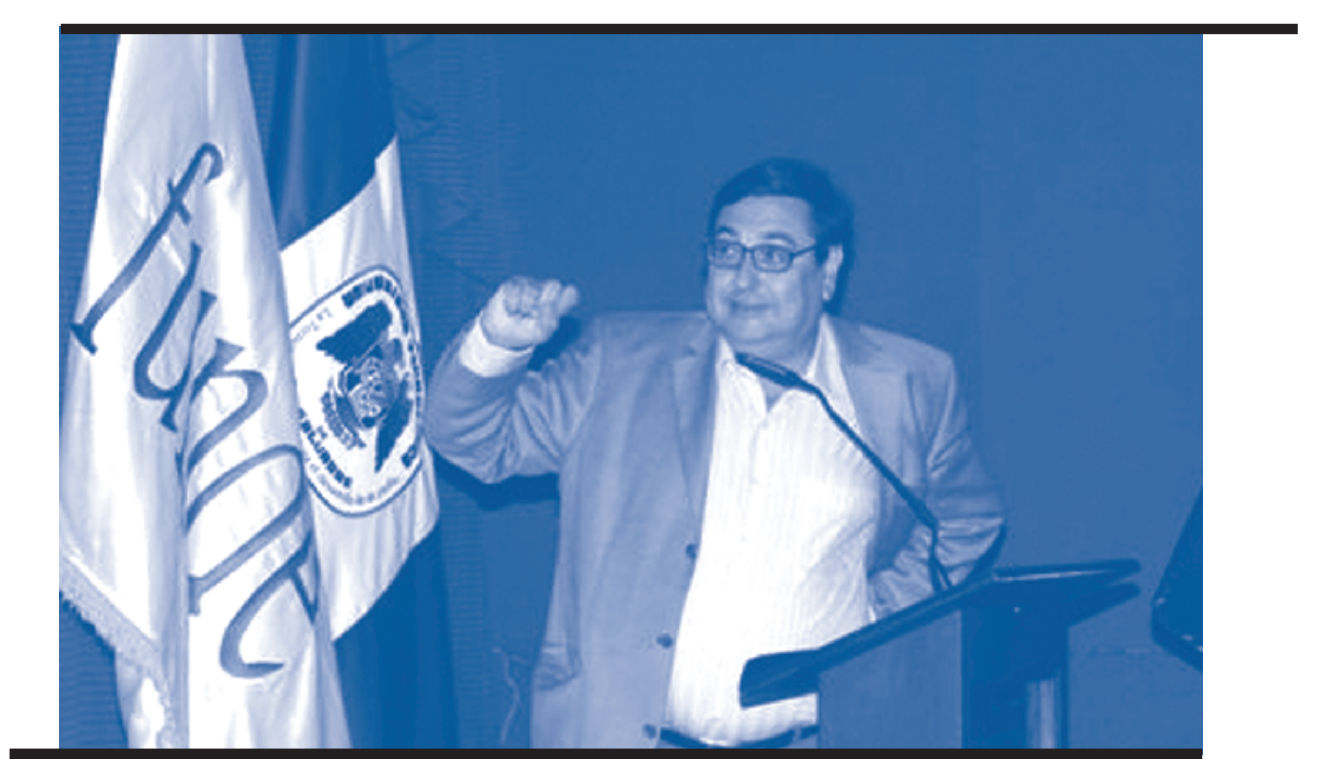




\section{ent ơrno}

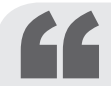

Generando

más ingresos $\mathbf{y}$

generando un gasto

mucho más eficaz y

eficiente y equitativo

me va generar más

crecimiento. El

Estado es un agente

que favorece la

competitividad de su

país o no la favorece.

Esas dos cosas nos

van ayudar a atacar 0

resolver. el PIB crezca, bueno pues puede ser. El punto es cómo, y con qué criterios, podemos establecer ahí criterios de equidad que es interesante, y luego también podemos intentar mejorar la capacidad de gestión tributaria.

\section{¿Cómo mejorar esa capacidad de gestión?}

Le voy a contar lo que se hace en España. Primero, tenemos un sistema de acceso a la gestión pública, en donde medir todas las limitaciones e imperfecciones humanas sea el objetivo; por lo tanto, es más probable que accedan personas más preparadas. Luego dotando - en el caso de la Agencia Tributaria Española- de dos cosas de suficiente independencia y algo que es inevitable: sueldos evidentemente atractivos como para que vayan los más capaces. Eso hay que tenerlo claro que para tener un servicio eficiente de recaudación hay que plantearse también que hay que incentivar al personal que trabaja ahí. Eso sí, la Agencia Tributaria Española en poco tiempo avanzó muchísimo, con esos criterios.

Después de puesta en marcha la aplicación de las nuevas políticas, ¿cuánto tiempo pasó para que vieran los frutos de una buena gestión?

Alrededor de unos 10 años a 12 años, antes cuando yo iba en los 70 a Francia se veía como otro planeta, ya en los 80 y 90, ya no había diferencia.

En España se está trabajando mucho con políticas públicas y género, concretamente en las políticas fiscales, ¿cómo están en el tema?

Realmente, desde el Instituto se está trabajando bastante en esa área. Hemos tenido múltiples investigaciones y publicaciones. La verdad es que se ha empujado el tema, porque hay compañeras con gran capacidad que han impulsado este tema. Ya hay dos instituciones públicas que están tendiendo presupuestos con equidad de género. 